\title{
How You Provide Corrective Feedback Makes a Difference: The Motivating Role of Communicating in an Autonomy-Supporting Way
}

\author{
Athanasios Mouratidis, ${ }^{1}$ Willy Lens, ${ }^{1}$ \\ and Maarten Vansteenkiste ${ }^{2}$ \\ ${ }^{1}$ University of Leuven; 2 University of Gent
}

\begin{abstract}
We relied on self-determination theory (SDT; Deci \& Ryan, 2000) to investigate to what extent autonomy-supporting corrective feedback (i.e., feedback that coaches communicate to their athletes after poor performance or mistakes) is associated with athletes' optimal motivation and well-being. To test this hypothesis, we conducted a cross-sectional study with 337 (67.1\% males) Greek adolescent athletes (age $M=15.59, S D=2.37$ ) from various sports. Aligned with SDT, we found through path analysis that an autonomy-supporting versus controlling communication style was positively related to future intentions to persist and well-being and negatively related to ill-being. These relations were partially mediated by the perceived legitimacy of the corrective feedback (i.e., the degree of acceptance of corrective feedback), and, in turn, by intrinsic motivation, identified regulation, and external regulation for doing sports. Results indicate that autonomy-supporting feedback can be still motivating even in cases in which such feedback conveys messages of still too low competence.
\end{abstract}

Keywords: sport psychology, autonomous and controlled regulation, corrective feedback, well-being, athletes

Two novice tennis players, Maria and Demetra, are trying to learn the overhead shot in badminton. As they are in the first stages of learning, they are making a lot of mistakes. Their coach tries to remedy their flawed performance by providing them corrective information. She does so in an empathetic and supporting way, so the two learners feel at ease and eager to further try improving their skills. These examples stand in contrast to Jack's situation. Jack is a very talented starter in a national-level football team. Nevertheless, each time he performs below the standards set by his coach, his coach shows his disappointment and even starts to shout on the field to point out his mistakes. Although Jack initially does his best

Athanasios Mouratidis is with the Department of Psychology, University of Leuven, Leuven, Belgium. Willy Lens is with the Department of Psychology, University of Leuven, Leuven, Belgium. Maarten Vansteenkiste is with the Department of Psychology, University of Gent, Gent, Belgium. 
to improve when confronted with the critical comments of his coach, throughout the season, he becomes more and more disappointed, frustrated, and demotivated.

The athletes described in the above examples all receive some kind of feedback from their coaches in response to their poor performance or their mistakes. Although the messages they receive contain information about how to improve their performance, the way these messages are articulated is quite different and, hence, might be differently associated with their response to this corrective feedback. But, is this really the case? Can corrective feedback provided by a coach in response to poor performance or after mistakes have a differential effect on motivational and emotional outcomes depending on the way it is perceived? In the present crosssectional study, we aim to elaborate on the motivational and emotional correlates of corrective feedback. Specifically, we used the self-determination theory (SDT) framework (Deci \& Ryan, 2000) to investigate whether an autonomy-supporting versus controlling style of communicating corrective feedback can foster or undermine, respectively, optimal motivation and adjustment.

\section{The Motivating Role of Feedback}

Herein, we define corrective feedback as statements that convey messages of how to improve after poor performance or mistakes. We distinguish corrective feedback from negative (or failure) feedback: whereas corrective feedback focuses more on the process, that is, on the aspects of one's performance that one fails to enact well or the aspects of one's performance that need remediation during achievement strivings, negative feedback focuses on the end result and, particularly, on one's failure to achieve a certain outcome. We relied for this definition of corrective feedback on Amorose and Weiss (1998), who showed that feedback containing information of low performance can be differentiated depending on the extent to which it conveys, among others, criticism (e.g., "That was awful"), information (e.g., "You need to keep an eye on the ball"), or neutral statements (e.g., "That was wrong").

Although the relation of positive and negative feedback to outcomes is well established in the extant literature (Deci, Koestner, \& Ryan, 1999), less is known about the relation of corrective feedback to motivational correlates. With respect to the beneficial impact of positive feedback, Deci and associates showed several decades ago that university students who received experimentally induced positive feedback exhibited more intrinsically motivated behavior compared with students in a control group in which they did not receive such positive feedback (Deci, 1972; see also Butler, 1987). Moreover, other studies showed that providing feedback that one has achieved high relative to average levels of performance standards resulted in higher levels of competence perceptions (Harackiewicz, Manderlink, \& Sansone, 1984). Since then, numerous studies have replicated these findings, showing a consistent positive association between positive feedback and self-reported interest and behaviorally assessed free-choice persistence (Deci et al., 1999).

With respect to negative feedback, experimental studies have also shown that negative competence-related feedback results in adverse outcomes such as decreases in satisfaction after solving math problems with a new technique (Senko \& Harackiewicz, 2005), less favorable evaluations of one's efforts and oneself after an anagram task (Jussim, Soffin, Brown, Ley, \& Kohlhepp, 1992), less free-choice behavior and enjoyment for a puzzle-solving task (Vansteenkiste \& Deci, 2003), 
and decreased self-confidence and attentional focus after a motor task (Brewer, Van Raalte, Linder, \& Van Raalte, 1991).

Apart from the consequences of competence-related feedback on motivation, several studies have identified factors that may moderate these effects. For instance, it has been shown that positive feedback yields more beneficial effects if the positive feedback (a) is communicated in an autonomy-supporting rather than a controlling way (Ryan, 1982); (b) is perceived as honest; (c) is focused on selfreferenced improvement rather than on normative performance (Butler, 1987); (d) is referring to successful attempts for tasks that are specific and realistic (Henderlong \& Lepper, 2002); and (e) if the feedback provider is perceived as prestigious, trustworthy, and proficient (Bandura, 1977). Accordingly, the effects of feedback on motivation may be moderated by recipients' characteristics, such as self-esteem (Smith \& Smoll, 1990), self-efficacy (Nease, Mudgett, \& Quiñones, 1999), selfhandicapping (Thompson, 2004), previous levels of performance (Monteil, Brunot, \& Huguet, 1996), and personal achievement goal orientation (Elliott, Shell, Henry, $\&$ Maier, 2005). What remained relatively unexplored in the feedback literature, however, is the way in which corrective feedback can be communicated and what the consequences are of different communication styles. This was our explicit aim in the current study.

\section{How to Communicate Corrective Feedback}

In particular, we focused on how corrective feedback, which involves pointing out faults and weaknesses to improve the learner's skills, can be communicated in a motivating way. This is an important issue because the provision of corrective feedback is often inevitable as it is inherently tied with the learning process. Theoretically, corrective feedback can be conceptually understood as an aspect of structure, and specifically as competence-related information that is provided during or after task engagement (Reeve, 2006). A critical question concerns then whether there are indeed different styles of communicating corrective feedback after poor performance or mistakes and if so, whether they differentially effect upon motivation, interest, and well-being. In line with previous research (e.g., Jang, Reeve, \& Deci, 2010; Sierens, Vansteenkiste, Goossens, Soenens, \& Dochy, 2009), the current contribution thus aims to investigate whether the way of communicating negative competence-related feedback in particular and providing structure in general plays a role in how the feedback will be accepted and which motivational correlates it will yield.

Although not taking the SDT perspective, a host of observational and crosssectional sport-related studies have shown that corrective feedback can be communicated in an autonomy-supporting fashion, for instance through empathy support, acknowledgment of feelings (Darst, Zakrajsek, and Mancini, 1989), and the display of need-supporting nonverbal behavior (e.g., patting the athletes on the back-see Rankin, 1989). Alternatively, corrective feedback can be provided in a controlling way, for instance, through the use of criticism and punishment (Amorose \& Horn, 2000; Black \& Weiss, 1992); nonverbal criticism (Allen \& Howe, 1998); scolding, nonverbal punishment, and negative modeling (e.g., mimicking an error in player's technique; see Lacy \& Darst, 1985); and nonverbal controlling behavior (e.g., tapping or frowning; see Rankin 1989). In few of these studies it was additionally evidenced that certain coach behaviors such as punitive measures 
and behaviors are independent from supporting behaviors with only the latter being positive predictors of desired outcomes such as favorable attitudes toward the sport and the coach. In sum, these findings provide some indirect support to our claim that corrective feedback after low performance or mistakes can be communicated in an either autonomy-supporting or controlling tone and that these different communication styles can have different effects on athletes' motivation and well-being.

Based on SDT, we equally expect the way in which the corrective feedback is perceived matters. Thus, it is reasonable to assume that, similarly to the way in which positive feedback is conveyed (Ryan, 1982), corrective feedback can be communicated in an either controlling or autonomy-supporting way. Specifically, corrective feedback in response to athletes' errors or low performance will be perceived by the athletes as directive and pressuring when coaches use a controlling style to convey their corrective messages. For instance, when communicating corrective feedback, coaches might induce guilt (e.g., "It's high time you stop doing that; I've told you over and over again to. ..."), shame (e.g., "Even a small child could see that you ignored your opponent's position."), conditional regard (e.g., "Why should I care about you? You neglected again my advice to. ..."), or threats of punishment (e.g., "You won't make it onto the team if you don't work on when and how to throw 3-point shots."). Clearly, controlling coaches do have an agenda and a set of (performance) standards they are trying to impose on their athletes. So, coaches who use a controlling style pressure their athletes to act in particular ways, such that athletes are likely to feel they have no other choice than to do something about their poor performance and to do it in the specific, prescribed way. Presumably, such a controlling corrective feedback will likely be perceived by athletes as critical, person-focused, and, even as unfair, threatening, and even humiliating.

Conversely, when corrective feedback is provided in an autonomy-supporting way it is likely that the feedback will be perceived as more legitimate, less threatening, and less demotivating. Autonomy-supporting coaches try to provide a desired amount of options and choice, coach from the players' internal frame of reference, and give a meaningful rationale in case choice is constrained (Deci, Eghrari, Patrick, \& Leone, 1994). Applied to the issue of providing corrective feedback, autonomy-supporting coaches would provide a meaningful and specific rationale for the corrective information so that the athlete understands why the feedback is given. In addition, they would try to take into account the athletes' perspective visà-vis their performance, for instance by soliciting the athlete's opinion about his or her performance or by asking how their corrective comments were received by the athlete. Finally, when the corrective feedback is clearly understood, autonomysupporting coaches would perhaps allow choice with respect to how and at what pace their athletes could work on their shortcomings.

Thus, we argue that the same corrective feedback would engender a greater willingness (i.e., autonomous motivation) to rectify the faults if it were to be communicated in a more accepting, respectful, and sympathetic, (i.e., autonomy-supporting) rather than a controlling way. There is some indirect support for this position in the literature, although most previous studies took place in educational rather than sport settings. For instance, Kamins and Dweck (1999) experimentally provided negative feedback to kindergartners in a person-oriented fashion, thereby telling the kindergartners that they had disappointed the experimenter, or in a process-oriented fashion, thereby telling the kindergartners that they failed because of the wrong 
strategy that they had followed. The authors found that, relative to person-centered criticism, process-oriented criticism (i.e., feedback that attributed failure to wrong strategy) resulted in lower levels of kindergartners' negative affect, higher levels of their persistence, and higher self-rated performance and self-assessment of their traits and abilities. Along similar lines, Baron (1988) showed that experimentally manipulated constructive negative feedback (which contained encouragement and sympathetic content-related statements, and which was devoid of any threatening statement or any reference to the cause of participants' inferior performance) relative to destructive negative feedback (which contained general and unsympathetic statements, including threats and attributions of participants' poor performance to internal factors) provoked less anger and tense, less conflict, and higher levels of self-efficacy and self-set goals on a subsequent task.

Herein, we additionally argue that the degree of acceptance-that is, the perceived legitimacy of the provided corrective feedback - might help to explain why an autonomy-supporting, relative to a controlling, communication mode would yield differential motivational effects. The concept of perceived legitimacy (i.e., degree of acceptance) prevails in social domain theory (Smetana, 1988). Within this framework, children (or athletes) perceive as legitimate the authority of their parents (or coaches) depending on the issues (e.g., personal, moral, conventional) the parents (or coaches) try to regulate. In line with Soenens, Vansteenkiste, and Niemiec (2009), we argue that the perceived legitimacy of the corrective feedback depends on the communication style coaches employ to regulate this issue. We considered perceived legitimacy as highly relevant to the issue of communication style of corrective feedback because, if coaches provide a reasonable and credible rationale for their corrective feedback, it is likely that athletes will feel understood and might see the value of the provided corrective statements, leading them to accept the provided feedback and thus to perceive the feedback as legitimate. In contrast, when communicated in a controlling way, it is less likely that the corrective information will be perceived as legitimate and fair because the corrections are imposed upon the athletes. Thus, although corrective feedback in general can be perceived as legitimate (or illegitimate) by athletes for various reasons, we expect that an autonomy-supporting communication style of corrective feedback will render it more legitimate.

Moreover, we anticipate that perceived legitimacy would, in turn, relate to higher and lower levels of autonomous (i.e., intrinsic motivation and identified regulation) and controlled motivation (i.e., introjected and external regulation), respectively. Autonomous motivation refers to behaviors that people exhibit when they feel agents of their own behavior, whereas controlled motivation refers to behaviors that individuals demonstrate when they feel coerced due to some internal or external psychologically pressuring reasons (Deci \& Ryan, 2000). When being confronted with corrective feedback, athletes might decide to freely put additional effort in the activity to rectify their faults and improve their skills or they might feel like they have no other choice than to do so. If one perceives the provided corrective feedback as legitimate, it is likely that one is more willing to voluntarily work on one's mistakes and faults rather than feeling forced to do so, such that one maintains a sense of psychological freedom and autonomy in the process. Further, higher levels of autonomous motivation would also be maintained when the feedback is perceived as legitimate because one is more likely to recognize one's weaknesses 
without feeling overwhelmed or personally hurt by the corrective statements, such that one maintains a sense of confidence in improving one's faults.

\section{The Present Research}

In the current study, we aimed to explore an integrated process model that considers the association between corrective feedback variables (namely, amount and autonomy-supporting versus controlling communication style of corrective competence-related feedback), degree of acceptance of feedback (i.e., perceived legitimacy), self-regulated motivation (that is, intrinsic motivation, identified regulation, introjected regulation, and external regulation), and motivational correlates, namely, intentions to persist and well-being. We invited regularly training athletes from various sports, to participate in the study because these athletes are more likely to routinely receive corrective feedback from their coaches with respect to their performance.

Based on SDT (Deci \& Ryan, 2000), we predicted that autonomy-supporting corrective feedback would be positively related to intrinsic motivation and identified regulation and negatively related to introjected and external regulation (Black \& Weiss, 1992; Cumming, Smith, \& Smoll, 2006) and that these associations would be accounted for by the extent to which corrective feedback is perceived as legitimate. In turn, we anticipated that intrinsic motivation and identified regulation on the one hand and external regulation on the other hand would be, respectively, positively and negatively related to emotional adjustment. We hypothesized that after controlling for external regulation, introjected regulation would yield null relation to emotional adjustment (Lonsdale, Hodge, \& Rose, 2008; Wilson, Rodgers, Blanchard, \& Gessell, 2003) because we expected that the pattern of correlations between the four self-regulated motivations and well-being would become gradually less negative (or null) and then more positive as one moves from less internalized to more internalized forms of motivation (i.e., from external regulation to introjected regulation and from identified regulation to intrinsic motivation, respectively).

As for athletes' self-reported intentions to persist, both types of autonomous motivation were expected to yield a positive association to it, while external regulation would be negatively related to it. Given that internally pressuring forces might lead one to put initial effort in an activity in the short term but not in the long term (Pelletier, Fortier, Vallerand, and Brière, 2001), we expected introjected regulation to yield no relation to intentions to persist in the future. We considered perceived legitimacy as an antecedent of different regulatory subtypes because the more athletes feel that the corrective feedback is legitimate, the more likely they will volitionally try to improve their skills and the less likely they will feel forced to do so.

\section{Method}

\section{Participants and Procedures}

An institutional approval to conduct the study was granted by the University of Leuven and an informed consent was first obtained from participants (or from their parents for those who were under 18 years old). Participants were 337 (67.1\% 
males; 4 athletes did not report their gender) Greek athletes (mean age: 15.59, $S D=2.37)$. The athletes came from various sports: basketball $(26.4 \%)$; football (24.9\%); volleyball (22.3\%); rowing $(9.5 \%)$; swimming and water polo $(4.8 \%)$; track and field (4.5\%); gymnastics (2.4\%); and other Olympic sports such as wrestling, boxing, tae-kwon-do, and sailing (4.5\%). The athletes belonged to teams of various levels, ranging from regional levels to the Greek national team level. On average, athletes had been participated in their sport activity for 5.88 years $(S D=$ $3.13)$ and trained for approximately $10.23 \mathrm{hr}$ per week $(S D=6.79)$ at the time of data collection. Athletes filled in the following questionnaires, all of which were adjusted and translated in the Greek language in accordance with the guidelines suggested by Hambleton (1994).

\section{Measures}

Self-Regulation-Sports. The Behavioral Regulation in Sport Questionnaire (BRSQ; Lonsdale et al., 2008) was adjusted to assess the autonomous and controlling reasons for which athletes are engaged in sports. Athletes responded on a 5-point scale $(1=$ not at all true of me; 5 = very true of me $)$ to what extent they participated in sports for intrinsic reasons (4 items; e.g., "because I like it"; $\alpha=.80$ ); for integrated reasons (4 items; e.g., "because sport is a part of who I am"; $\alpha=.74$ ); for identified reasons (4 items; e.g., "because I find it personally meaningful"; $\alpha=.74)$; for introjected-approach and introjected-avoidance reasons (8 items; "because I would feel proud /ashamed if I do /did not do sports"; $\alpha=.75$ ); and for external reasons (8 items; e.g., "because others force me to play"; $\alpha=.82$ ).

A confirmatory factor analysis (CFA) for a five-factor (i.e., intrinsic motivation, integrated, identified, introjected, and external regulation) model resulted in poor fit: $\mathrm{S}-\mathrm{B} \chi^{2}(367, N=302)=924.66, p<.01, \mathrm{CFI}=.762, \mathrm{NNFI}=.737$, SRMR $=.102$, RMSEA $=.071$ (90\% CI: .065-.077). To remediate this poor fit and after inspecting the major causes of misfit, we proceeded to the following modifications. First, we dropped integrated regulation because it was highly correlated to identified regulation $(r=.81, p<.01)$. In addition, we drop two out of the four introjected-approach items and another two (out of four) external-approach items because Lagrange-multiplier test showed that they needed to cross-load to identified and introjected regulation, respectively. In addition, we allowed the errors of two intrinsic motivation items to covary because in retrospect we realized that these two items ("Because I like it" and "Because I enjoy it") were very similarly phrased. The CFA for the revised four-factor model with six introjected regulation items ( $\alpha$ $=.73)$ and six external regulation items $(\alpha=.83)$ yielded a marginally acceptable fit $(\mathrm{CFI}=.929, \mathrm{NNFI}=.917, \mathrm{SRMR}=.063, \mathrm{RMSEA}=.046$ [90\% CI: .036-.056]), although the model-reproduced covariance matrix failed to reproduce the observed one: $\mathrm{S}-\mathrm{B} \chi^{2}(163, N=317)=273.31, p<.01$. Thus, based on this revised model we computed an average score for the four self-regulated forms of motivation.

Corrective Feedback. We devised a new scale to assess the experienced amount of corrective feedback, the perceived communication styles and legitimacy associated with the corrective feedback. Specifically, for each of these three measures we used four sets of items. First, athletes indicated on a scale ranging from 1 (I totally disagree) to 5 (I totally agree) to what extent they received corrective feedback from their coaches (e.g., "My coach makes me aware of my weak points"; $\alpha=.68$ ). After 
each of the four items assessing the amount of corrective feedback, we asked athletes to indicate to what extent their coaches communicated this corrective feedback in an autonomy-supporting style (4 items; $\alpha=.54$ ) and specifically (a) whether they provide rationale to their athletes for things that should be done (e.g., "My coach gives a meaningful reason why he says this), (b) whether they take the perspective of their athletes (e.g., "My coach listens to what I think about it myself"), and (c) whether they provide choices to them (e.g., "My coach indicates that there are different possibilities to do something about it") or a controlling communication style ("My coach says I should be ashamed of myself"; $\alpha=.79$ ) For each item we computed a score of relative autonomous communication style by subtracting the controlling style from the autonomous communication style. The Cronbach alpha of the relative autonomy-supporting communication style four-item subscale was .74. Finally, students indicated to what extent they perceived the corrective feedback as legitimate (e.g., "When my coach points out my shortcomings, I find it justified"; $\alpha$ $=.52$ ). Because of the low internal consistency of perceived legitimacy, we retained only two items that showed a better, yet marginal, internal consistency $(\alpha=.58)$. A CFA for a three-factor (i.e., amount, relative autonomy-support, and perceived legitimacy of corrective feedback) model with a two-indicator latent factor of perceived legitimacy showed marginal fit: $\mathrm{S}-\mathrm{B} \chi^{2}(33, N=308)=72.14, p<.01, \mathrm{CFI}$ $=.918, \mathrm{NNFI}=.886, \mathrm{SRMR}=.062, \mathrm{RMSEA}=.062(.042-.081)$.

Perceived Coaching Feedback. In an attempt to validate our assessment of corrective feedback, we assessed also athletes' perceptions of coach behaviors by using 9 out of the 12 items from the Coaching Feedback Questionnaire (CFQ), which is based on the Coaching Behavior Assessment Questionnaire (CBAS; Smith, Smoll, \& Hunt, 1977; see Hagger \& Chatzisarantis, 2007). Specifically, we asked athletes to indicate on a 7-point Likert-type scale $(1=$ Never $; 7=$ Always $)$ to what extent their coaches used the following behaviors when they interacted with their athletes: (i) reward, (ii) no-reward, (iii) encouragement after mistakes, (iv) corrective instruction, (v) punishment, (vi) corrective instruction and punishment, (vii) ignoring mistakes, (viii) keeping control (i.e., maintain discipline), and (ix) instructions. Most of the obtained correlations were in the expected direction, providing initial validity evidence for our newly devised scales. For instance, amount of corrective feedback was positively related to instructions $(r=.26, p$ $<.01)$, keeping control $(r=.21, p<.01)$, and corrective instruction $(r=.33, p$ $<.01)$, whereas it was negatively related to ignoring mistakes $(r=-.22, p<.01)$ and no-reward (i.e., lack of positive feedback after good performance; $r=-.23, p$ $<$.01). In addition, relative autonomy-support corrective feedback was positively related to reward (i.e., positive feedback after good performance; $r=.39, p<.01$ ), encouragement after mistakes $(r=.44, p<.01)$, and corrective instruction $(r=$ $.27, p<.01)$, whereas it was negatively related to no-reward $(r=-.35, p<.01)$, punishment $(r=-.47, p<.01)$, and corrective instruction along with punishment $(r=-.39, p<.01)$.

Subjective Vitality. We used the scale from Ryan and Frederick (1997) to assess to what extent athletes felt energized and vigorous during the last few weeks. An example item of this 5-point $(1=$ Not at all true of $m e ; 5=$ Very true of $m e)$, 7-item scale was "The last few weeks I felt very energetic when doing sports." The internal consistency was .91. 
Positive and Negative Affect. We adjusted the Positive and Negative Affect Scale (PANAS; Watson, Clark, \& Tellegen, 1988) to gauge the positive and negative affect athletes experienced in the past few weeks. Ten items $(1=$ Not at all true of $m e ; 5=$ Very true of me) were used to assess positive affect (e.g., "During the past few weeks I felt cheerful"; $\alpha=.82$ ) and another 10 items to assess negative affect (e.g., "During the past few weeks I felt ashamed"; $\alpha=.83$ ).

Depression. We adjusted the Center for Epidemiological Studies-Depression Scale (CES-D; Radloff, 1977) to assess to what extent athletes experienced depressive feelings in the last few weeks (10 items; e.g., "During the last few weeks I felt sad"; $\alpha=$.74). Depressive feelings were assessed on a 4-point Likert scale $(0=$ rarely or none of the time [less than one day]; $1=$ a couple of times [1-2 days]; 2 = sometimes or regularly [3-4 days]; and $4=$ most or all of the time [5-7 days]).

Free-Choice Behavioral Intentions. Assuming that intentions can serve as a proxy of one's behavior (Ajzen, 2001), we assessed athletes' intentions to persist in their sport activity. Thus, similarly to previous studies (e.g., Vansteenkiste, Simons, Soenens, \& Lens, 2004), we asked athletes to report to what extent they aimed at (a) being involved in their sport activity and (b) training at the same pace and even more in the upcoming season. The two items were positively interrelated $(r=.72)$ and the Cronbach alpha for this two-item measure was .84.

\section{Results}

\section{Preliminary Analyses}

Table 1 provides information about descriptive statistics and bivariate correlations of the variables of the study. As can be noticed, amount, autonomy-supporting communication style, and perceived legitimacy of corrective feedback were positively interrelated. Moreover, amount of corrective feedback was positively associated with intrinsic motivation, identified regulation, and positive affect and negatively associated with depression. Autonomy-supporting corrective feedback and perceived legitimacy were also positively related with intrinsic motivation and negatively related to external regulation. Perceived legitimacy was also positively associated to identified regulation. Both autonomy-supporting feedback and perceived legitimacy as well as intrinsic motivation were positively related to behavioral intentions and positive affect and vitality and inversely related to negative affect and depression. In addition, identified and introjected regulation were positively linked with behavioral intentions and positive affect, whereas external regulation was negatively related to intentions and positively related to negative affect and depression.

Because all the subsequent analyses are based on the assumption that the athletes did receive corrective feedback from their coaches, we decided to exclude the athletes who scored below the midpoint (i.e., $\leq 3$ on the used 5-point scale) on the amount of corrective feedback. We thus dropped 19 athletes (5.6\% of the sample) from further consideration although ancillary analyses showed only negligible differences between the full and the trimmed $(N=318)$ sample. We additionally conducted a MANOVA to test for gender differences in the reported variables. Given that the MANOVA test was significant-Wilks's $\Lambda=.836, F(10,295)=5.77$, 


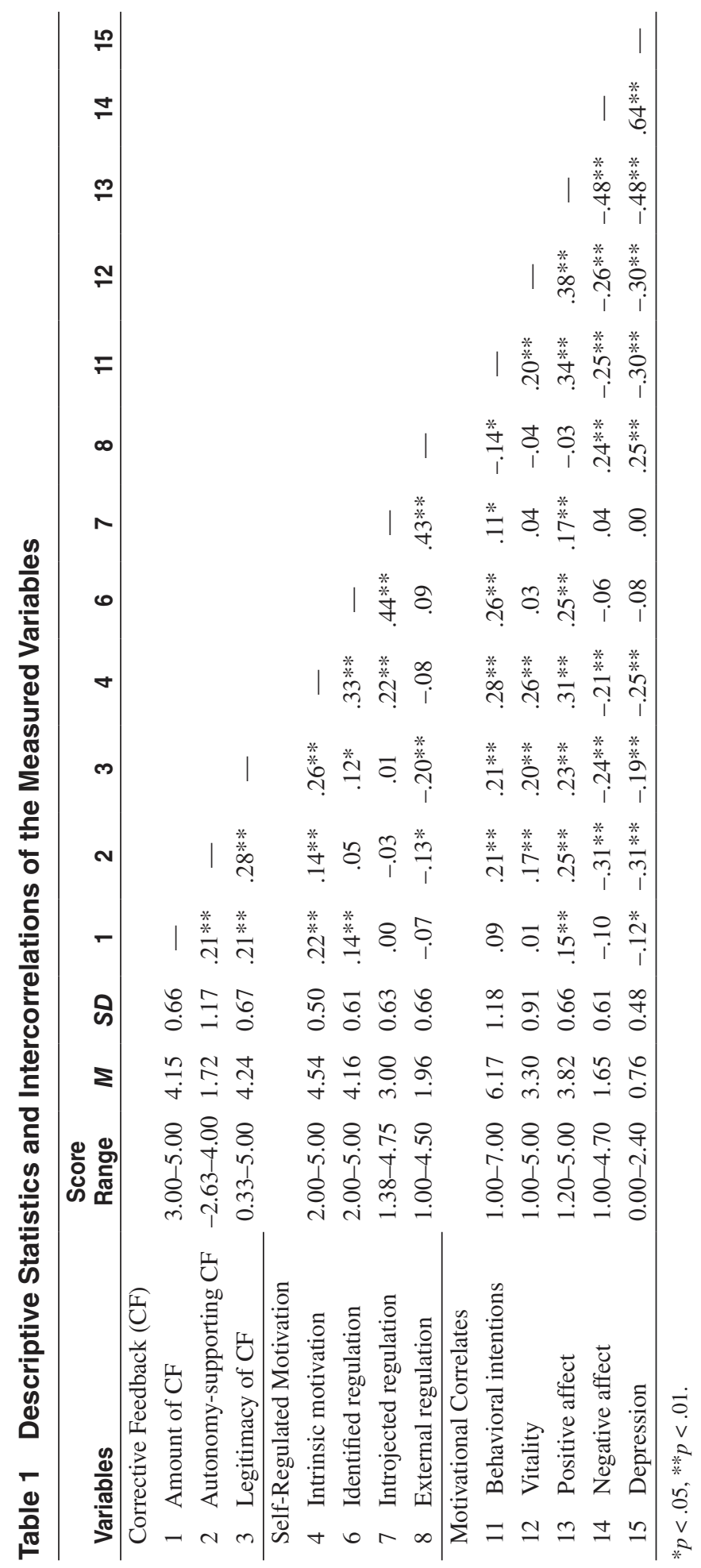


$p<.01$, multivariate $\eta^{2}=.16$ - gender was included as an additional covariate in the subsequent analyses.

\section{Primary Analyses}

Our main hypothesis holds that (relative) autonomy-supporting corrective feedback would be positively related to the degree to which athletes perceive this feedback as legitimate, which in turn would be related to intentions to persist and well-being through the mediation of autonomous (positively) and controlled (negatively) motivation. To test this hypothesis, we conducted a path analysis of our hypothesized model in which gender was entered as covariate and in which, similar to previous studies (e.g., Standage, Duda, \& Ntoumanis, 2005), we allowed the residuals among the four self-regulated forms of motivation to covary. Likewise, in that model the residuals between well-being and ill-being were allowed to covary because indices of well-being, like positive affect and vitality, and indices of ill-being, like negative affect and depression, are considered to represent, respectively, the positive and the negative aspect of subjective well-being.

The originally hypothesized model did not fit the data well; S-B $\chi^{2}=(41, N$ $=306)=93.55, p<.01, \mathrm{CFI}=.909, \mathrm{SRMR}=.075, \mathrm{RMSEA}=.065,(90 \% \mathrm{CI}$ : .047-.082). Inspection of the Lagrange-multiplier test indicated that the model would be considerably improved if we modified the model as follows. First, the model fit would be improved if we allowed amount of corrective feedback to covary with autonomous style of corrective feedback. We deemed this modification as justifiable because most coaches are more likely to use an autonomy-supportive instead of a controlling style to communicate when they interact with their athletes (Pelletier et al., 2001). Second, the model fit would be improved if we allowed the residuals of intentions to covary with the residuals of well-being and ill-being, a modification in line with previous studies (e.g., Kwan \& Bryan, 2010). Third, the model would be further improved if we dropped all the nonsignificant paths, mainly (a) the path linking perceived legitimacy with introjected regulation and (b) the a priori hypothesized path that was expected to inversely link external regulation to intentions and well-being. Dropping this path could be justified from previous studies which showed lack of consistent (negative) relation between controlled forms of motivation and positive outcomes (Lonsdale et al., 2008, Wilson et al., 2003), while controlled motivation has been found to yield a positive association with negative outcomes.

Fourth, and more important, the model would be substantially improved if we drew direct paths from autonomy-support corrective feedback to the three motivational correlates, behavioral intentions, well-being, and ill-being. In fact, this modification suggested that perceived legitimacy and self-regulated motivation only partially mediated the relation between autonomy supporting corrective feedback and motivational outcomes. We deemed this modification as justifiable and consistent to our major hypothesis and thus we revised our model by allowing also a direct relation of autonomy supporting corrective feedback to intentions, well-being, and ill-being. The variance-covariance matrix of this model adequately reproduced the observed data, $\mathrm{S}-\mathrm{B} \chi^{2}=(45, N=306)=63.36, p=.04$, and yielded better fit indices CFI $=.968, \mathrm{SRMR}=.049$, RMSEA $=.037,(90 \%$ CI: $.010-.056)$ compared with the originally hypothesized model of our hypothesis $\left(\Delta \chi^{2} / d f=7.55, p<.01\right)$. 
This model is shown in Figure 1. As we hypothesized, apart from the amount of corrective feedback the degree to which athletes perceived such corrective feedback as autonomy-supporting was positively related to perceived legitimacy. These perceptions of legitimacy were positively associated with intrinsic motivation and identified regulation, unrelated to introjected regulation, and negatively associated with external regulation. In turn, intrinsic motivation and identified regulation were positively linked with intentions to persist; intrinsic motivation was also positively related to well-being and negatively related to ill-being and a similar pattern was found for autonomy-supporting corrective feedback. In contrast, external regulation was positively related to ill-being, whereas, introjected regulation showed no relation to motivational correlates. Concerning gender differences, the model confirmed the MANOVA findings as a few paths between gender and measured variables were found to be significant (not shown in Figure 1). Specifically, females were less likely to report that they received autonomy supporting corrective feedback $(\beta=-.18$, $z=-2.90, p<.01 ; M=1.44, S D=1.35)$ than males $(M=1.87, S D=1.03)$ and less likely to report intrinsic motivation $(\beta=-.15, z=-2.41, p<.01 ; M=4.45$, $S D=0.57$ vs. $M=4.59, S D=0.43)$, identified regulation $(\beta=-.19, z=-3.02$, $p<.01 ; M=4.01, S D=0.70$ vs. $M=4.25, S D=.052)$, but also introjected regulation $(\beta=-.19, z=-3.40, p<.01 ; M=2.42, S D=0.73$ vs. $M=2.71, S D=0.71)$. In addition, females exhibited a less adaptive emotional pattern as they were less likely to report well-being $(\beta=-.20, z=-2.78, p<.01 ; M=3.40, S D=0.67)$ and more likely to report ill-being $(\beta=.27, z=4.74, p<.01 ; M=1.39, S D=0.53)$ than males $(M=3.63, S D=0.63$ and $M=1.10, S D=0.42$, respectively $)$.

\section{Discussion}

In this paper we investigated to what extent the corrective feedback that coaches convey to athletes after poor performance or mistakes is perceived by athletes as autonomy-supporting or controlling and, if so, how such a perception of feedback is associated to two types of autonomous and two types of controlled motivation and further to positive and negative affective reactions and behavioral intentions. Consistent to the basic tenets of cognitive evaluation theory, a subtheory of SDT (Deci \& Ryan 1985), we found that athletes' perceptions of the autonomy support that they received from their coaches was positively associated with athletes' autonomous motivation and through this with intentions to persist and well-being. Although there is abundant evidence in the literature about this relation, the present research has shown that this link still holds in instances in which the coaches convey corrective feedback to their athletes. This finding highlights the importance of autonomy provision for athletes' motivation even in those cases in which competence perceptions might be jeopardized because of corrective feedback.

Self-determination theory (Deci \& Ryan, 2000) assumes that although autonomy, competence, and relatedness need-supporting contexts are all necessary for individuals to integrate originally externally regulated behaviors, autonomy support plays a critical role. This is because one has to experience personal freedom and choice over one's actions to become self determined and well adjusted. Positive competence-related feedback is important but inadequate for optimal motivation because if one is coerced to demonstrate one's competence one will be less than optimally motivated (Deci \& Ryan, 2000). Alternatively, one might hypothesize 


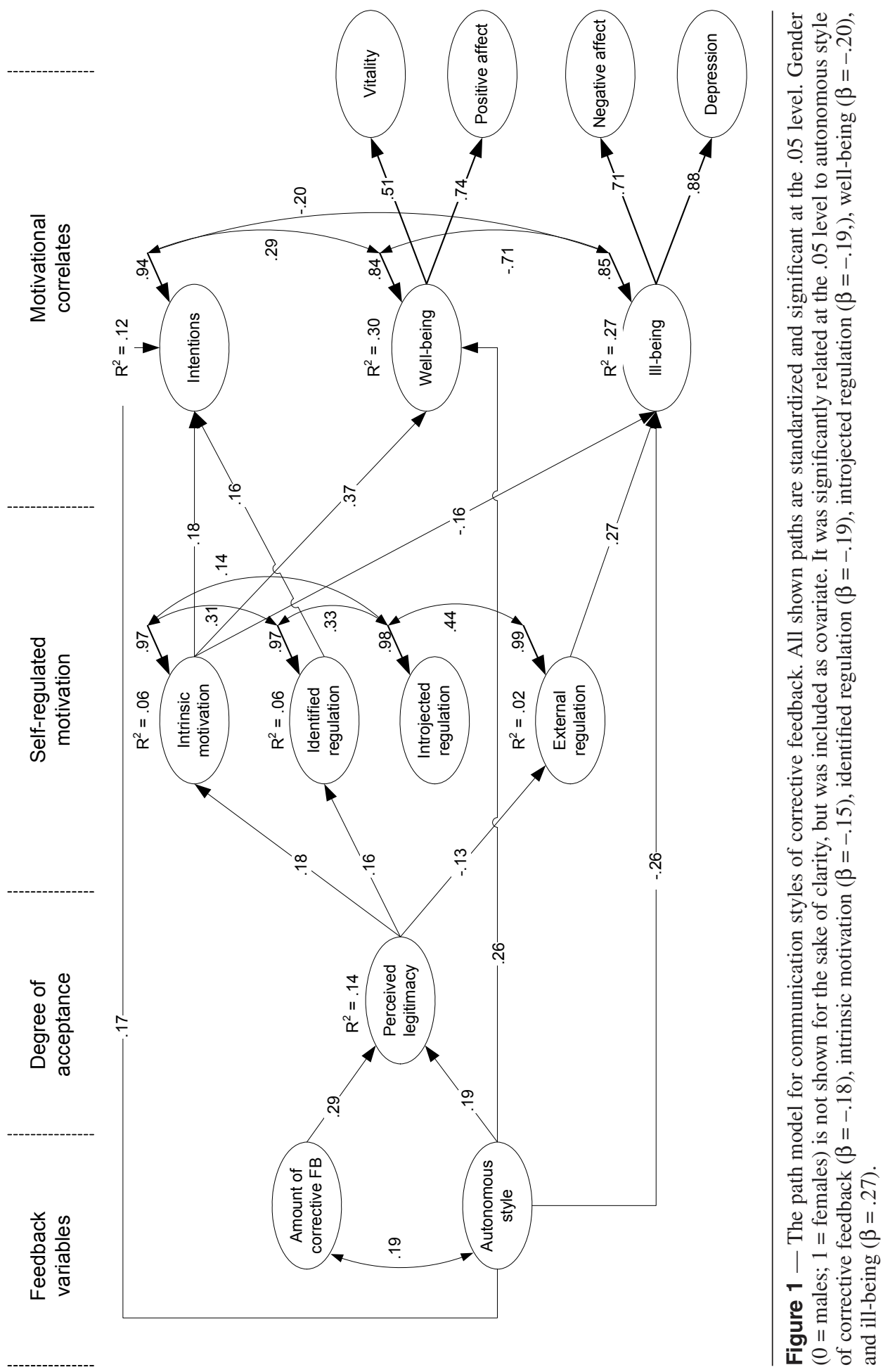


that being informed that one should develop and train one's competencies in a given situation or for a given achievement task may not undermine one's motivation as long as one is informed in a respectful, considerate, and autonomy-supporting manner. Feelings of psychological freedom and volition are then experienced also during unsuccessful personal strivings. From a practical standpoint, our findings are noteworthy because they show how the sometimes necessary but potentially debilitating provision of competence-related feedback after poor performance or errors can be administered without jeopardizing athletes' motivation and wellbeing. This possibility seems more likely to occur in competitive settings that are evaluative in nature (Senko \& Harackiewicz, 2002). Coaches might be eager to agree, even without being well aware of the SDT, that facilitating their athletes feel competent is important in keeping them on track. However, coaches might become skeptical when they confront situations in which their athletes perform worse than expected or worse relative to some standards. Obviously, in such situations they need to provide some corrective information to aid their athletes improve their performance, but this information may transmit messages of lower competence, which in turn might subvert their athletes' motivation-especially those with a tendency to perceive such comments focusing on stable traits (see Weiner, 1985). How can they resolve this problem in which the provision of corrective feedback after errors or low performance is necessary but potentially harmful?

Our findings indicate that coaches can provide the necessary corrective information to their athletes if they convey it in an autonomy-supporting manner. If they do not do so, the corrective feedback is less likely to be associated with autonomous motivation and favorable outcomes. Thus, coaches might need to know that taking the perspective of their athletes, allowing choice about how to overcome the faults (Deci \& Ryan, 1991; Mageau \& Vallerand, 2003), and providing a rationale for the suggested weak points are effective strategies that will prevent their athletes from being discouraged by the provided corrective information.

It should be underscored that the present relation of autonomy-supporting communication style of corrective feedback to autonomous motivation and external regulation and, in turn, to intentions to persist, well-being, and ill-being, was partially mediated by perceived legitimacy. Apparently, coaches should not only intervene after athletes' poor performance or mistakes in an autonomy-supporting way but they need also to ensure that their corrective feedback is perceived as legitimate. Obviously, the degree to which feedback is perceived as legitimate is influenced by other factors also such as the content of the feedback (e.g., when it is specific, sets attainable goals, focuses on lack of improvement or learning and not on social comparisons, and attributes poor performance to lack of effort or strategy use and not to abilities), its timing, the degree to which it is genuine and sincere, and the trustworthiness of the feedback provider (Bandura, 1977; Henderlong \& Lepper, 2002). In addition, as our current research shows, the amount of corrective feedback may be also positively related to the degree to which it is accepted and hence to the degree to which it may facilitate athletes' quality of motivation.

Two additional points that need to be addressed concern the pattern of relations of identified regulation to well-being and the patterns of relations of introjected and external regulation to outcomes. Although the lack of relation between identified regulation and well-being when intrinsic motivation is concurrently considered failed to confirm our initial hypothesis, it was partly consistent with previous 
studies. In fact, Burton, Lydon, D’Alessandro, and Koestner (2006) have similarly demonstrated that, when jointly considered, intrinsic motivation but not identified regulation is positively associated to indices of well-being like positive affect. In addition, path analysis showed that external (but not introjected) regulation was positively associated to ill being and that both of them were unrelated to desired outcomes such as well-being or intentions. Although we expected that external regulation in particular would be negatively related to positive outcomes, this finding is not surprising given that previous research has shown that only introjected regulation but also external regulation too is not consistently related to positive outcomes (e.g., Lonsdale et al., 2008; Wilson et al., 2003). Thus, it seems athletes may still carry out sport activities even when they feel pressured to do so but at a high emotional cost (in case of these pressures are external to their selves) or without feeling vitalized or in good mood (in case these pressures are internal to their selves).

Furthermore, introjected regulation appeared to be neither positively related (as intrinsic motivation or identified regulation did) nor negatively related (as external regulation did) to the degree of acceptance of corrective feedback (i.e., perceived legitimacy; see Figure 1). This lack of relation implies that athletes with an internal psychological pressure may do sports irrespective of the extent to which they perceive this feedback as legitimate. In addition, our findings are in line with a previous study which showed no relation between introjected regulation and intentions to persist in the long term (Pelletier et al., 2001), presumably because we assessed intentions in a way that seems to correspond to the long-term persistence, as the questions pertained to participants' intentions to engage in their sport in the upcoming season. Certainly, future studies need to address whether introjected and external regulation are selectively linked with some outcomes but not with others (Koestner \& Losier, 2002) and how these associations evolve across time.

Overall, although this pattern of relation was obtained from cross-sectional data and thus although it conveys a one-shot picture, it might depict an internalization process as autonomy-supporting corrective feedback was positively associated to intrinsic motivation and identified regulation, not related to introjected regulation, and negatively related to external regulation. Aligned with cognitive evaluation theory (Deci \& Ryan, 1985), athletes are more likely to become autonomous motivated as long as they continue experiencing an autonomy supporting context and future research with longitudinal designs may need to examine whether communication style of corrective feedback does indeed facilitate an internalization process.

Concerning gender differences, we found that females reported lower levels of positive affect and higher levels of negative affect and depression than males. Females also reported that they received less autonomy-supporting corrective feedback and that they were less motivated in general. Previous cross-cultural research has shown that females are more likely to report feelings of depression and anxiety, but also more positive feelings than males (Costa, Terracciano, \& McCrae, 2001). How then can those previous findings coincide with the present ones showing that females reported not only more depression and negative affect but also less positive affect than males?

A possible explanation for these gender differences may be due to the gender differences favoring males in autonomy-supporting corrective feedback. Previous 
research (e.g., Deci, 1972) showed that females benefited less from receiving verbal reinforcement, in general. Hence, apart from females' tendency to experience more negative affect, it is possible that female athletes report lower levels of emotional adjustment because, compared with males, they were less likely to perceive their coaches' corrective feedback as autonomy supportive. Obviously, more research is needed in testing likely gender differences in the relation of autonomy-supporting and controlling styles of corrective feedback to affective outcomes.

\section{Limitations}

Several limitations of the present research should be noted. First, despite the causal relationship implied through path analysis, the data are correlational. A reciprocal relationship thus is equally likely to exist between an autonomysupporting communication style of corrective feedback and correlates. Similarly to the relation between positive feedback and performance in which feedback recipients might just try to fulfill feedback providers' expectations (see Pelletier \& Vallerand, 1996), it is possible that recipients of autonomy-supporting corrective feedback might just try to confirm their coaches' strivings by reporting more optimal motivation and emotional regulation. It is also likely that optimally motivated athletes will elicit more autonomy-supporting forms of corrective feedback from their coaches each time they perform poorly. Future longitudinal studies controlling for athletes' initial levels of motivational and emotional regulation could perhaps sort out how different forms of corrective feedback lead to different outcomes.

Second, we tested our model by means of path analysis and not by means of a full latent structural model. Likewise, and because of the low Cronbach alpha of the autonomy-supporting subscale, we did not assess the independent relation of autonomy-supporting and controlling corrective feedback as within the (relative) autonomy supporting corrective feedback we included both the measures of autonomy supporting and controlling communication types of corrective feedback. Certainly, subsequent studies need to recruit a larger number of athletes to examine the hypothesized relationships through full latent SEM. In addition, we did not include autonomy, competence, and relatedness need satisfaction. This omission hindered us from testing whether the satisfaction of the three basic psychological needs mediates the relation between autonomysupporting communication styles of corrective feedback and self-determined motivation, well-being, and ill-being.

\section{Conclusions}

As in every human activity, mistakes or poor performance are inescapable during training or competition and the corrective information in response to such mistakes or poor performance may inherently convey messages of low competence that may endanger athletes' motivation and affect-based adjustment. Aligned with SDT however, we showed that if such feedback is communicated in an autonomy supporting way it is associated to optimal forms of motivation and emotional regulation. 


\section{References}

Ajzen, I. (2001). Nature and operation of attitudes. Annual Review of Psychology, 52, 27-58.

Allen, J.B., \& Howe, B.L. (1998). Player ability, coach feedback, and female adolescent athletes' perceived competence and satisfaction. Journal of Sport \& Exercise Psychology, 20, 280-299.

Amorose, A.J., \& Horn, T.S. (2000). Intrinsic motivation: Relationships with collegiate athletes' gender, scholarship status, and perceptions of their coaches' behavior. Journal of Sport \& Exercise Psychology, 22, 63-84.

Amorose, A.J., \& Weiss, M.R. (1998). Coaching feedback as a source of information about perceptions of ability: A developmental examination. Journal of Sport \& Exercise Psychology, 20, 395-420.

Bandura, A. (1977). Self-efficacy: Toward a unifying theory of behavioral change. Psychological Review, 84, 191-215.

Baron, R.A. (1988). Negative effects of destructive criticism: Impact on conflict, self-efficacy, and task performance. The Journal of Applied Psychology, 73, 199-207.

Black, S.J., \& Weiss, M.R. (1992). The relationship among perceived coaching behaviors, perceptions of ability, and motivation in competitive age-group swimmers. Journal of Sport \& Exercise Psychology, 14, 309-325.

Brewer, B.W., Van Raalte, J.L., Linder, D.E., \& Van Raalte, N.S. (1991). Peak performance and the perils of retrospective introspection. Journal of Sport \& Exercise Psychology, 8, 227-238.

Burton, K.D., Lydon, J.E., D’ Alessandro, D.U., \& Koestner, R. (2006). The differential effects of intrinsic and identified motivation on well-being and performance: Prospective, experimental, and implicit approaches to self-determination theory. Journal of Personality and Social Psychology, 91, 750-762.

Butler, R. (1987). Task-involving and ego-involving properties of evaluation: Effects of different feedback conditions on motivational perceptions, interest, and performance. Journal of Educational Psychology, 79, 474-482.

Costa, P.T., Terracciano, A., \& McCrae, R.R. (2001). Gender differences in personality traits across cultures: Robust and surprising findings. Journal of Personality and Social Psychology, 81, 322-331.

Cumming, S.P., Smith, R.E., \& Smoll, F.L. (2006). Athlete-perceived coaching behaviors: Relating two measurement traditions. Journal of Sport \& Exercise Psychology, 28, 205-213.

Darst, P.W., Zakrajsek, D.B., \& Mancini, V.H. (1989). Interaction analysis: A system for coding direct and indirect teaching behaviors. In P.W. Darst, D.B. Zarkajsek, \& V.H. Mancini (Eds.), Analyzing Physical Education and Sport Instruction (2nd ed., pp. 95-105). Champaign, IL: Human Kinetics.

Deci, E.L. (1972). Intrinsic motivation, extrinsic reinforcement, and inequity. Journal of Personality and Social Psychology, 22, 113-120.

Deci, E.L., Eghrari, H., Patrick, B.C., \& Leone, D.R. (1994). Facilitating internalization: The self-determination theory perspective. Journal of Personality, 62, 119-142.

Deci, E.L., Koestner, R., \& Ryan, R.M. (1999). A meta-analytic review of experiments examining the effects of extrinsic rewards on intrinsic motivation. Psychological Bulletin, 125, 627-668.

Deci, E.L., \& Ryan, R.M. (1985). Intrinsic motivation and self-determination in human behavior. New York: Plenum.

Deci, E.L., \& Ryan, R.M. (1991). A motivational approach to self: Integration in personality. In R. Dienstbier (Ed.), Nebraska symposium on motivation: Vol. 38. Perspectives on motivation (pp. 237-288). Lincoln, NE: University of Nebraska Press.

Deci, E.L., \& Ryan, R.M. (2000). The "What" and "Why" of goal pursuits: Human needs and the self-determination of behavior. Psychological Inquiry, 11, 227-268. 
Elliott, A.J., Shell, M.M., Henry, K.B., \& Maier, M.A. (2005). Achievement goals, performance contingencies, and performance attainment: An experimental test. Journal of Educational Psychology, 97, 630-640.

Hagger, M.S., \& Chatzisarantis, N.L.D. (2007). The trans-contextual model of motivation. In M.S. Hagger \& N.L.D. Chatzisarantis (Eds.), Intrinsic Motivation and SelfDetermination in Exercise and Sport (pp. 54-70). Champaign, IL: Human Kinetics.

Hambleton, R.K. (1994). Guidelines for adapting educational and psychological tests: A progress report. European Journal of Psychological Assessment, 10, 229-240.

Harackiewicz, J., Manderlink, G., \& Sansone, C. (1984). Rewarding pinball wizardry: Effects of evaluation and cue value on intrinsic interest. Journal of Personality and Social Psychology, 47, 287-300.

Henderlong, J., \& Lepper, M.R. (2002). The effects of praise on children's intrinsic motivation: A review and synthesis. Psychological Bulletin, 128, 774-795.

Jang, H., Reeve, J., \& Deci, E.L. (2010). Engaging students in learning activities: It's not autonomy support or structure, but autonomy support and structure. Journal of Educational Psychology. 102, 588-600.

Jussim, L., Soffin, S., Brown, R., Ley, J., \& Kohlhepp, K. (1992). Understanding reactions to feedback by integrating ideas from symbolic interactionism and cognitive evaluation theory. Journal of Personality and Social Psychology, 62, 402-421.

Kamins, M.L., \& Dweck, C.S. (1999). Person versus process praise and criticism: Implications for Contingent self-worth and coping. Developmental Psychology, 35, 835-847.

Koestner, R., \& Losier, G.F. (2002). Distinguishing three ways of being internally motivated: A closer look at introjection, identification, and intrinsic motivation. In E.L. Deci \& R.M. Ryan (Eds.), Handbook of self-determination research (pp. 101-121). Rochester, NY: The University of Rochester Press.

Kwan, B.M., \& Bryan, A.D. (2010). Affective response to exercise as a component of exercise motivation: Attitudes, norms, self-efficacy, and temporal stability of intentions. Psychology of Sport and Exercise, 11, 71-79.

Lacy, A.C., \& Darst, P.W. (1985). Systematic observation of behaviors of winning high school head football coaches. Journal of Teaching in Physical Education, 4, 256-270.

Lonsdale, C., Hodge, K., \& Rose, E.A. (2008). The behavioral regulation in sport questionnaire (BRSQ): Instrument development and initial validity evidence. Journal of Sport \& Exercise Psychology, 30, 323-355.

Mageau, G.A., \& Vallerand, R.J. (2003). The coach-athlete relationship: A motivational model. Journal of Sports Sciences, 21, 883-904.

Monteil, J.M., Brunot, S., \& Huguet, P. (1996). Cognitive performance and attention in the classroom: An interaction between past and present academic experiences. Journal of Educational Psychology, 88, 242-248.

Nease, A.A., Mudgett, B., \& Quiñones, M.A. (1999). Relationships among feedback sign, self-efficacy, and acceptance of performance feedback. The Journal of Applied Psychology, 84, 806-814.

Pelletier, L.G., Fortier, M., Vallerand, R.J., \& Brière, N.M. (2001). Associations among perceived autonomy support, forms of self-regulation, and persistence: A prospective study. Motivation and Emotion, 25, 279-306.

Pelletier, L.G., \& Vallerand, R.J. (1996). Supervisors' beliefs and subordinates' intrinsic motivation: A behavioral confirmation analysis. Journal of Personality and Social Psychology, 71, 331-340.

Radloff, L.S. (1977). The CES-D scale: A self-report depression scale for research in the general population. Applied Psychological Measurement, 1, 385-401.

Rankin, K.D. (1989). The Rankin interaction analysis system (RIAS). In P.W. Darst, D.B. Zarkajsek, \& V.H. Mancini (Eds.), Analyzing physical education and sport instruction (2nd ed., pp. 107-111). Champaign, IL: Human Kinetics.

Reeve, J. (2006). Teachers as facilitators: What autonomy-supportive teachers do and why their students benefit. The Elementary School Journal, 106, 225-236. 
Ryan, R.M. (1982). Control and information in the intrapersonal sphere: An extension of cognitive evaluation theory. Journal of Personality and Social Psychology, 43, 450-461.

Ryan, R.M., \& Frederick, C. (1997). On energy, personality, and health: Subjective vitality as a dynamic reflection of well being. Journal of Personality, 65, 529-565.

Senko, C., \& Harackiewicz, J.M. (2002). Performance goals: The moderating roles of context and achievement orientation. Journal of Experimental Social Psychology, 38, 603-610.

Senko, C., \& Harackiewicz, J.M. (2005). Regulation of achievement goals: The role of competence feedback. Journal of Educational Psychology, 97, 320-336.

Sierens, E., Vansteenkiste, M., Goossens, L., Soenens, B., \& Dochy, F. (2009). The interactive effect of perceived teacher autonomy-support and structure in the prediction of self-regulated learning. The British Journal of Educational Psychology, 79, 57-68.

Smetana, J.G. (1988). Adolescents' and parents' conceptions of parental authority. Child Development, 59, 321-335.

Smith, R., \& Smoll, F. (1990). Self-esteem and children's reactions to youth sport coaching behaviors: A field study of self-enhancement processes. Developmental Psychology, 26, 987-993.

Smith, R., Smoll, F., \& Hunt, E. (1977). A system for the behavioral assessment of athletic coaches. Research Quarterly, 48, 401-407.

Soenens, B., Vansteenkiste, M., \& Niemiec, C. (2009). Should parental prohibition of adolescents' peer relationships be prohibited? Personal Relationships, 16, 507-530.

Standage, M., Duda, J.L., \& Ntoumanis, N. (2005). A test of self-determination theory in school physical education. The British Journal of Educational Psychology, 75, 411-433.

Thompson, T. (2004). Re-examining the effects of noncontingent success on self-handicapping behaviour. The British Journal of Educational Psychology, 74, 239-260.

Vansteenkiste, M., \& Deci, E.L. (2003). Competitively contingent rewards and intrinsic motivation: Can losers remain motivated? Motivation and Emotion, 27, 273-299.

Vansteenkiste, M., Simons, J., Soenens, B., \& Lens, W. (2004). How to become a persevering exerciser? Providing a clear, future intrinsic goal in an autonomy supportive way. Journal of Sport \& Exercise Psychology, 26, 232-249.

Watson, D., Clark, L.A., \& Tellegen, A. (1988). Development and validation of brief measures of positive and negative affect: The PANAS scales. Journal of Personality and Social Psychology, 54, 1063-1070.

Weiner, B. (1985). An attributional theory of achievement motivation and emotion. Psychological Review, 92, 548-573.

Wilson, P.M., Rodgers, W.M., Blanchard, C.M., \& Gessell, J. (2003). The relationship between psychological needs, self-determined motivation, exercise attitudes, and physical fitness. Journal of Applied Social Psychology, 33, 2373-2392.

Manuscript received: December 15, 2009

Revision accepted: May 15, 2010 